\title{
Teste Rápido para Diağnóstico da Infecção pelo HIV em Parturientes
}

\author{
Rapid HIV Testing in Parturients
}

Rui Lara de Carvalho, Cláudio Krahe, Gabriele Farina,

Daniela de Oliveira Paula, Neuza Richetti, Tiago Crossetti

\begin{abstract}
RESUMO
Objetivos: determinar o valor preditivo positivo de um teste rápido para anticorpos contra o HIV denominado Determine ${ }^{\mathrm{TM}}$ (Abott) em gestantes internadas em trabalho de parto entre $1^{\circ}$ de agosto de 2001 e 5 de outubro de 2002.

Métodos: foram incluidas neste estudo as parturientes que não haviam sido submetidas a exames para a detecção do HIV durante a gestação ou que não apresentavam os resultados disponíveis no momento da internação. A amostra de sangue foi colhida no momento da internação, na sala de admissão, e o teste rápido foi realizado e comparado com o padrão ouro (ELISA e Western blot).

Resultados: entre as 298 gestantes avaliadas, o teste rápido foi positivo em 16 pacientes (5,3\%). Os resultados foram confirmados pelos testes de ELISA e Western blot em 12 pacientes (4\%). Todos os exames negativos foram avaliados pelos testes ELISA e Western blot. O teste apresentou sensibilidade de 100\%, especificidade de 98\%, valor preditivo positivo de $75 \%$ e valor preditivo negativo de $100 \%$.

Conclusões: estes dados mostram o valor do teste rápido para a detecção de infecção por HIV em situações de emergência, como o parto, de gestantes não testadas previamente
\end{abstract}

PALAVRAS-CHAVE: Infecções na gravidez. AIDS. Transmissão vertical. HIV.

\section{Introdução}

A transmissão vertical é a principal via de infecção pelo HIV na população infantil ${ }^{1}$. No Brasil, esta forma de transmissão é responsável por mais de $90 \%$ dos casos notificados de AIDS $^{2}$. Isso ocorre, entre outros motivos, porque a cobertura de realização de testes para o HIV no período prénatal é muito inferior ao desejado, sendo ainda menor nas gestantes mais vulneráveis para a infecção pelo HIV em decorrência, principalmente, de fatores como a baixa adesão ao pré-natal. Em outras palavras, para a maioria das gestantes portadoras do HIV, a única oportunidade de acesso à avaliação sorológica, aconselhamento e profilaxia

Serviço de Obstetrícia do Hospital São Lucas da Pontifícia Universidade Católica do Rio Grande do Sul (HSL-PUCRS).

Correspondência:

Cláudio Krahe

Rua Estácio de Sá 490

91330-430 - Porto Alegre - RS

Fone: (51) 3338-3843 - Fax: (51) 3311-3380

e-mail:ckrahe@terra.com.br da transmissão vertical é na hora do parto. Estima-se que 15 a $30 \%$ das crianças, nascidas de mulheres infectadas, adquirem o vírus por não ter sido realizada a profilaxia e que a intervenção com drogas anti-retrovirais (ARV) durante a gravidez, no trabalho de parto e no início da vida do recémnascido reduz de maneira importante a transmissão vertical (50 a 70\%) (3,4 $^{3,}$ incidência de infecção pelo HIV nas mulheres atendidas nas maternidades de Porto Alegre (RS) é de aproximadamente 2 a 3\%5,6. Estima-se que 33,6 milhões de pessoas apresentam a infecção pelo HIV ou AIDS ${ }^{7}$. Nos Estados Unidos, estima-se que 6.000 a $7.000 \mathrm{mu}-$ lheres infectadas dão à luz anualmente ${ }^{7}$.

Estudos planejados estão sendo realizados para avaliar diferentes maneiras de reduzir a transmissão do HIV da mãe para o feto ${ }^{8}$. O índice de gestantes que recebem cuidados pré-natais com teste para HIV ainda é baixo ${ }^{9}$. Na Tailândia, por exemplo, os índices são de $7,3 \%{ }^{10}$. No Centro de Saúde Mental e Médico de Lincoln em Nova Iorque, observouse que $42,3 \%$ das mães não portavam documentação de teste para o HIV no momento do parto, tanto 
pela falta de assistência no período pré-natal, pela falha no oferecimento do exame, quanto pela ausência de anotações na carteira da gestante ${ }^{7}$.

Uma grande barreira para a implementação do uso de drogas ARV em gestantes infectadas pelo HIV é a falta de assistência pré-natal ${ }^{10}$. O momento da transmissão do vírus da mãe para o feto é crucial, e deve-se intervir com drogas ARV durante o trabalho de parto bem como administrá-las posteriormente ao recém-nascido. Além disso, a amamentação deve ser proibida ${ }^{8}$. No Brasil, embora as drogas ARV estejam disponíveis para toda a população de gestantes infectadas pelo HIV e seus filhos, as dificuldades da rede pública ${ }^{2}$ em prover diagnóstico laboratorial desta infecção e a cobertura insuficiente de mulheres testadas no pré-natal resultam na administração de zidovudina injetável em menos de $50 \%$ dos partos de gestantes provavelmente infectadas pelo $\mathrm{HIV}^{11}$. As rotas possiveis para a transmissão vertical do vírus são: intra-útero transplacentária pela circulação materna; intraparto, durante o trabalho de parto e o parto propriamente dito, pela inoculação ou ingestão de sangue ou outros líquidos infectados (como o líquido amniótico); pós-parto, via amamentação ${ }^{6}$. Observou-se que o tratamento com drogas ARV após as 36 semanas de gestação e durante o parto, além do tratamento de recém-nascidos via oral assim como a proibição do aleitamento, reduziu em 50\% a taxa de transmissão ${ }^{6,12}$. Quando utilizada somente intraparto, a zidovudina reduz a transmissão em menor porcentagem $(35 \%)^{12}$. A realização do teste rápido para HIV aumenta a proporção de pacientes que, com o resultado positivo, recebem aconselhamento pós-teste de maneira segura e confiável ${ }^{13}$. Assim, este teste veio preencher uma lacuna entre a assistência pré-natal e o tratamento adequado em unidade hospitalar ${ }^{7}$. Metade das pacientes portadoras do HIV está naquele grupo de mulheres que não receberam ou tiveram mínima assistência pré-natal ${ }^{2,12}$.

Os testes intraparto para o HIV se mostraram rápidos, de baixo custo, altamente específicos e sensíveis, fáceis de executar e de interpre$\operatorname{tar}^{10}$. Estudos em diversos países mostraram índices de $100 \%$ de sensibilidade, 99,8\% de especificidade, $97,5 \%$ de valor preditivo positivo e $100 \%$ de valor preditivo negativo ${ }^{14}$. O teste rápido oferece inúmeras vantagens, dentre elas a de fornecer o resultado preciso em poucos minutos, permitindo aconselhamento materno e ação imediata por parte de médicos e outros profissionais de saú$\mathrm{de}^{14}$. Os indices de resultados falso-positivos são de $0,14 \%^{10}$, o que é considerado esperado se for estudada população de gestantes com alta prevalência.
Um estudo realizado nos centros de controle e prevenção de DSTs, da cidade de Dallas e do Estado de Geórgia, nos Estados Unidos, mostrou que não houve diferença significativa entre os resultados quando foi utilizado o teste rápido com confirmação pelo teste Western blot ${ }^{14}$. Os dois estudos relatam que a temperatura do local onde o teste é estocado e a correta centrifugação do soro são essenciais para garantir a sensibilidade e especificidade do teste. Quando a temperatura excede os $25^{\circ} \mathrm{C}$ (recomendados pelo fabricante), a ocorrência de casos falso-positivos aumenta. No entanto, não houve relato de casos de falso-negativos ${ }^{14}$. $\mathrm{O}$ teste rápido para o HIV mostrou relação positiva entre custo e benefício ${ }^{12}$.

Esta análise visou avaliar os resultados do teste rápido para HIV em uso na nossa instituição, avaliando a eficácia do método em gestantes internadas no centro obstétrico.

\section{Pacientes e Métodos}

Este é um estudo transversal, de teste diagnóstico. Foram avaliadas todas as gestantes em trabalho de parto admitidas no Hospital São Lucas da Pontifícia Universidade Católica do Rio Grande do Sul (HSL-PUCRS) e que não haviam sido avaliadas com teste para HIV ou não tinham o resultado à disposição no momento da admissão. O trabalho foi aprovado pela Comissão de Ética do HSL-PUCRS.

As seguintes variáveis foram estudadas: idade, município de residência, grau de escolaridade, recebimento ou não de cuidados pré-natais, idade gestacional na admissão hospitalar, raça, resultado do teste rápido e resultado do ELISA e Western blot. O período do estudo foi de $1^{\circ}$ de agosto de 2001 a 5 de outubro de 2002.

Foram excluídas as gestantes que se recusaram a participar do estudo quando informadas verbalmente das finalidades do mesmo e aquelas que já tinham resultados do teste para HIV no pré-natal.

No momento da internação, sangue periférico foi colhido da paciente e colocado no kit Determine $^{\mathrm{TM}} \mathrm{HIV}-1 / 2$ (Abbott). Este é um teste imunocromático de leitura visual para a detecção qualitativa de anticorpos do HIV-1 e HIV-2. A amostra é adicionada ao cartão do teste e, uma vez que ela migra através do conjugado, ela se reconstitui e se mistura com o conjugado de colóide de selênioantígeno. Essa mistura continua a migrar através da fase sólida para imobilizar os antígenos e peptídeos sintéticos na janela do paciente. Se os 
anticorpos para HIV-1 e/ou HIV-2 estiverem presentes na amostra, os anticorpos se ligarão no colóide de selênio-antígeno e no antígeno da janela do paciente, formando uma linha vermelha. Se os anticorpos para HIV-1 e/ou HIV-2 estiverem ausentes, o colóide de selênio-antígeno fluirá através da janela do paciente e nenhuma linha vermelha será formada. Uma barra de controle paralela e incorporada assegura a validade do ensaio.

Os soros de todas as pacientes foram submetidos ao teste ELISA e aquelas com teste positivo (Determine ${ }^{\mathrm{TM}}$ ) foram também avaliadas pelo teste Western blot, com aconselhamento pós-teste. Os dados obtidos foram analisados pelo pacote estatístico SPSS 9.0 para Windows. As variáveis paramétricas foram descritas por medidas de tendência central (média), e as categóricas, como proporções expressas em percentuais.

\section{Resultados}

O número de gestantes avaliadas foi 298. Do total de pacientes, 168 haviam recebido assistência pré-natal $(56,4 \%)$, com média de quatro consultas. Das 298 pacientes, 91 (30,5\%) afirmaram terem sido previamente testadas, mas os resultados não estavam disponiveis no momento da admissão na maternidade. A média de idade gestacional foi de 37 semanas e 2 dias (mínima de 22 e máxima de 42 semanas). A média de idade das pacientes foi de 24,8 anos, sendo a mínima de 14 e a máxima de 46 anos.

Quanto à origem das pacientes, Porto Alegre foi o município mais freqüente, com 53\%, seguido de Viamão (RS), com 39,9\%. Os demais municipios eram da grande Porto Alegre. O grau de escolaridade mais freqüente foi o primeiro grau incompleto (192 pacientes; 64,4\%), 18 pacientes eram analfabetas $(6,4 \%)$ e 2 pacientes tinham curso superior $(0,7 \%)$.

A maioria das parturientes era de raça branca $(154 ; 51,7 \%)$, seguida de negras, 86 (28,8\%), e pardas, 58 (19,5\%). Não haviam recebido assistência pré-natal 130 pacientes (43,6\%).

Na Tabela 1 é apresentada a distribuição das pacientes quanto à presença ou não de anticorpos anti-HIV. O teste rápido foi positivo em 16 pacientes $(5,3 \%)$ e confirmado pelos testes ELISA e Western blot em 12 pacientes (4,0\%). Todos os 282 $(98,6 \%)$ testes negativos ao teste rápido foram confirmados com o teste ELISA como sendo realmente negativos.
Tabela 1 - Teste rápido para detecção do HIV em parturientes e confirmação com teste ELISA e Western-blot.

\begin{tabular}{lcccccr}
\hline & & \multicolumn{4}{c}{ Confirmação } & \multicolumn{2}{c}{ Totais } \\
& HIV positivo & \multicolumn{2}{c}{ HIV negativo } & \multicolumn{2}{c}{ ( } \\
& $\mathbf{n}$ & $\%$ & $\mathbf{n}$ & $\%$ & $\mathbf{n}$ & $\%$ \\
\hline Teste + & 12 & 4,0 & 4 & 1,3 & 16 & 5,3 \\
Teste - & 0 & - & 282 & 94,7 & 282 & 94,7 \\
Total & 12 & 4,0 & 286 & 96,0 & 298 & 100,0 \\
\hline
\end{tabular}

\section{Discussão}

É reconhecida a importância do diagnóstico da infecção pelo HIV em gestantes, mesmo que tardiamente, durante o trabalho de parto ${ }^{15}$. O inicio da terapia ARV o mais precocemente possivel diminui as chances de contaminação do concepto $^{3,16 .}$

Nas 298 pacientes avaliadas, percebe-se que, embora 168 tivessem freqüentado pré-natal com média de quatro consultas, 91 haviam sido testadas para HIV mas os resultados não estavam disponiveis no momento da internação. Fica claramente evidenciada a necessidade de melhor treinar a equipe de atendimento pré-natal nas rotinas básicas aceitas atualmente ${ }^{17}$, bem como de estimular mais as pacientes para que façam pré-natal e portem consigo os documentos deste atendimento quando da internação em uma maternidade.

A realização de teste rápido para o diagnóstico das pacientes infectadas pelo HIV se mostrou fidedigno nos casos cujos resultados foram negativos, com sensibilidade e valor preditivo negativo de $100 \%$. Já nas pacientes com resultados positivos, a porcentagem de confirmação dos mesmos com os testes ELISA e Western blot foi de 75\%.

A avaliação rápida para HIV, com os testes disponiveis, é comparável aos testes ELISA de terceira geração disponíveis no momento, permitindo intervenção precoce para reduzir a transmissão vertical ${ }^{15}$. Por serem bastante sensiveis, podem apresentar alguns resultados falso-positivos.

As pacientes cujo teste rápido foi negativo para o HIV tiveram esse resultado confirmado pelo teste ELISA. Isso mostra o significativo valor preditivo negativo deste procedimento, que se torna de extrema valia, não somente em relação à segurança para o concepto, mas também em possíveis acidentes profissionais que venham a ocorrer no atendimento da paciente testada.

Este estudo demonstra a importância da realização do teste rápido para HIV na admissão à maternidade, devendo-se ressaltar que sua reali- 
zação deve ser proposta para as gestantes não testadas previamente, sendo fundamental realização voluntária e confidencial.

\section{ABSTRACT}

Objective: to evaluate the sensitivity and specificity of a rapid antibody HIV test (Determine ${ }^{T M}$ - Abott) for women in labor between August 1, 2001, and October 5, 2002.

Methods: all parturient women who had not been tested for the detection of HIV during pregnancy or had the result of an HIV test not available at admission were included in the present study. Blood samples were collected at the moment of admission, and the rapid test was carried out and compared with the gold standard (ELISA and Western blot).

Results: in 298 pregnant women assessed, the rapid test was positive in $16(5.3 \%)$, and the results were confirmed by ELISA and Western blot in 12 cases (4\%). All negative results were confirmed by the ELISA and Western blot tests.

Conclusions: the test presented 100\% sensitivity, 98\% specificity, $75 \%$ positive predictive value, and $100 \%$ negative predictive value. These data show the importance of the rapid test for the detection of HIV infection in emergencies, such as imminent delivery of non-previously tested pregnant women.

KEYWORDS: Infections in pregnancy. HIV and pregnancy. SIDA and pregnancy. Vertical transmission. Rapid HIV test.

\section{Referências}

1. Castilho EA, Bastos FI, Scwarcwald CL, Fonseca MGM. A AIDS no Brasil: uma epidemia em mutação. Cad Saúde Publica 2000; 16 (Suppl 1):4-5.

2. Marques HHS, Latorre MRDO, Della Negra M, Pluciennik AMA, Salomão MLM. Falhas na identificação da infecção pelo HIV durante a gravidez em São Paulo. Rev Saúde Pública 2002; 36:385-92.

3. Connor EM, Sperling RS, Gelber R, et al. Reduction of maternal-infant transmission of human immunodeficiency virus type 1 with zidovudine treatment. N Engl J Med 1994; 331:1173-80.

4. Shaffer N, Chuachoowong R, Mock PA, et al. Shortcourse zidovudine for perinatal HIV-1 transmission in Bangkok, Thailand: a randomised controlled trial. Lancet 1999; 353:773-80.

5. Goldani MZ, Giugliani ERJ, Scanlon T, et al. Aconselhamento e testagem voluntária para o HIV durante a assistência pré-natal. Rev Saúde Pública 2003; 37:552-8.
6. Secretaria Municipal da Saúde de Porto Alegre. Normas e rotinas para redução da transmissão vertical do HIV. Manual da Secretaria da Saúde. Porto Alegre; 2001

7. Rajegowda BK, Das BB, Lala R, Rao S, McNeeley DF. Expedited human immunodeficiency virus testing of mothers and newborns with unknown HIV status at time of labor and delivery. J Perinat Med 2000; 28:458-63.

8. Strategies for prevention of perinatal transmission of HIV infection. Siena Consensus Workshop II. J Acquir Immune Defic Syndr Hum Retrovirol 1995; 8:161-75.

9. Bergenstrom A, Sherr L. A review of HIV testing policies and procedures for pregnant women in public maternity units of Porto Alegre, Rio Grande do Sul, Brazil. AIDS Care 2000; 12:177-86.

10. Chalermchockcharoenkit A, Louisirirotchnakul S, Roongpisuthipong A, Sirimai K, Sutchritpongsa P, Wasi C. Rapid human immunodeficiency virus diagnostic test during the intrapartum period in pregnant women who did not receive antenatal care. J Med Assoc Thai 2002; 85:703-8.

11. Ministério da Saúde. Recomendações para a profilaxia da transmissão vertical do HIV e terapia anti-retroviral em gestantes. Brasília: CN-DST/ AIDS, 2002

12.Grobman WA, Garcia PM. The cost-effectiveness of voluntary intrapartum rapid human immunodeficiency virus testing for women without adequate prenatal care. Am J Obstet Gynecol 1999; 181:1062-71.

13.Wilkinson D, Wilkinson N, Lombard C, et al. Onsite HIV testing in resource-poor settings: is one rapid test enough? AIDS 1997; 11:377-81.

14.Kassler WJ, Haley C, Jones WK, Gerber AR, Kennedy EJ, George JR. Performance of a rapid, on-site human immunodeficiency virus antibody assay in a public health setting. J Clin Microbiol 1995; 33:2899902.

15. Nogueira SA, Lambert JS, Albuquerque AL, et al. Assessment of a rapid HIV test strategy during labor: a pilot study from Rio de Janeiro, Brazil. J Hum Virol 2001; 4:278-82.

16.Sperling RS, Shapiro DE, Coombs RW, et al. Maternal viral load, zidovudine treatment, and the risk of transmission of human immunodeficiency virus type 1 from mother to infant. N Engl J Med 1996; 335:1621-9.

17.Calleja JM, Walker N, Cuchi P, Lazzari S, Ghys PD, Zacarias F. Status of the HIV/AIDS epidemic and methods to monitor it in the Latin America and Caribbean region. AIDS 2002; 16 (Suppl 3):S3-12.

Recebido em: 19/9/2003

Aceito com modificações em: 5/4/2004 